\title{
Formação docente, reflexão e ação sobre a prática: as potencialidades de um curso EaD para coordenadores pedagógicos na formação de professores-orientadores
}

\author{
Natália de Lacerda Gill ${ }^{1}$, Caterine Fagundes ${ }^{2}$
}

\begin{abstract}
Resumo
Este artigo trata da formação docente e tem como objetivo refletir sobre as potencialidades e os limites para a formação de professores-orientadores de curso EaD. Buscou-se discutir as potencialidades do exercício reflexivo em diversos âmbitos: na formação dos cursistas (coordenadores pedagógicos de escolas públicas do Rio Grande do Sul que frequentaram esse curso), na formação de professores-orientadores desses cursistas e na formação docente das próprias autoras. Inicialmente, apresenta-se uma reflexão sobre aspectos da pesquisa na formação docente. Em seguida, descrevese o desenvolvimento de duas das salas ambientes do curso. Por fim, destaca-se o direcionamento dado aos trabalhos, tendo em vista os objetivos de formação de professores-orientadores. A análise aponta para a evidência da insuficiência de tempo e de ações no sentido da formação dos cursistas, com o fim de os preparar adequadamente para o desenvolvimento do TCC, ressaltando, por outro lado, a relevância da atuação no curso como processo de formação dos professores-orientadores.
\end{abstract}

Palavras-chave: formação docente; EaD; Escola de Gestores.

1 Mestre e doutora em Educação pela Universidade de São Paulo.

E-mail: natalia.gil@uol.com.br

2 Doutorado em Educação pela Universidade de Barcelona em Métodos de Pesquisa e Diagnóstico em Educação. Graduação em História pela PUC-RS. Pós-Doutorado pelo Programa Nacional doutoramento da CAPES junto ao Programa de Pós-Graduação em Políticas e Gestão de Processos Educacionais.

E-mail: caterine.fagundes@gmail.com 


\title{
Teachers training, reflection and action on the practice: the potentialities of a distance education course for pedagogic coordinators in the teacher-advisors' formation
}

\author{
Natália de Lacerda Gil, Caterine Fagundes
}

\begin{abstract}
This paper discusses teacher education and aims to reflect on the potentialities and some limits for the teacher-advisor formation in a distance education course. It aims to discuss the potentialities of the reflexive exercise in different areas: the students training for teaching (coordinators of public schools in Rio Grande do Sul, who attend this course), the teacher-advisor formation and training of authors themselves as teachers. Initially, it presents a reflection on the research in teacher education. Subsequently, it describes the development of the distance course. Finally, it focuses on the work considering the training objectives for teacher-advisors. The analysis points out to the evidence of insufficiency of time and actions towards the training of students in order to prepare them for the development of the Course Conclusion Paper. On the other hand, it emphasizes the importance of the practice in the training process for teacher-advisors course.
\end{abstract}

Keywords: teacher education; distance education; Managers School. 


\section{Introdução}

O professor precisa ser formado para enfrentar os desafios da novidade escolar contemporânea. Nessas condições, qualquer proposta de formação docente deve ter um sentido de investigação e de busca de novos caminhos. A premência do problema educacional não justifica o apressamento de soluções, que devem ter sempre o caráter de tentativas. (AZANHA, 2006, p. 63).

Pelo menos desde os anos 1990 temos discutido a importância e as especificidades da formação continuada de professores. Das várias proposições que figuraram na literatura especializada daquele período, provavelmente a mais estimulante tenha sido a que focalizava a formação do professor reflexivo como objetivo principal ${ }^{3}$. Nesse sentido, eram colocados em evidência os processos de reflexão e de pesquisa sobre a prática como constitutivos do fazer docente. Sem desconsiderar a importância dos saberes produzidos pelas ciências da educação - recentemente, sobretudo, nos meios acadêmicos - tais proposições reclamavam a urgência da valorização dos saberes da experiência e a necessidade de que os professores desenvolvessem competências no sentido de integrar os diversos saberes de que dispõem para a construção de sua identidade e de sua prática profissionais.

É partindo desse horizonte que este artigo inscreve suas análises e ponderações. Instituídas na função de coordenar a sala ambiente Metodologia do Trabalho Científico (MTC) e a orientação dos Trabalhos de Conclusão de Curso (TCC) do curso de Pósgraduação Lato sensu em Coordenação Pedagógica - 2ª edição (2015-2016) - no âmbito do Programa Nacional Escola de Gestores da Educação Básica ${ }^{4}$, as autoras puderam, para além de colocar em execução concepções sobre formação, pensar acerca do processo em si. O objetivo foi, portanto, investigar e colocar em discussão as potencialidades e os limites do exercício reflexivo em diversos âmbitos: na formação dos cursistas (coordenadores pedagógicos de escolas públicas do Rio Grande do Sul que frequentaram esse curso), na formação de parte dos professores-orientadores desses cursistas e na formação docente das próprias autoras. A metodologia ancorou-se na observação participante, visto ser "um método que nos permite aceder a situações e eventos comuns, sendo difícil de captar através de entrevistas ou através de instrumentos de auto-avaliação” (MÓNICO et. al., 2017, p. 725). Cabe ressaltar que, aqui, o foco investigativo foi o processo de formação dos formadores (orientadores dos Trabalhos de Conclusão de Curso), e não dos cursistas por eles orientados. Sendo assim, ao longo das reuniões coletivas e dos encontros individuais com cada formador, foram sendo observadas as participações e as reações de cada um naquilo que dizia respeito ao aprendizado de como orientar a pesquisa em educação. Nesse sentido, consideramos que

3 Para uma visão mais detalhada acerca do surgimento desse conceito e de sua apropriação no campo educacional, ver artigo de Tatiana Bezerra Fagundes (2016).

4 Realizado na Universidade Federal do Rio Grande do Sul. 
[...] a opção metodológica pela observação de tipo participante responde ao objetivo de proceder, dentro das realidades observadas, a uma adequada participação dos investigadores, de forma "não intrusiva”, e de modo a reduzir a variabilidade residual, nomeadamente a repressão de emoções extravasadas ou comportamentos efetuados, bem como a artificialidade dos mesmos" (MÓNICO et. al., 2017, p. 726).

Razão pela qual essa nos pareceu uma metodologia adequada ao processo de pesquisa pretendido.

$\mathrm{O}$ artigo se organiza em três partes. Na primeira, pretendeu-se retomar brevemente a discussão teórica acerca da importância da reflexão e da pesquisa na formação docente. Na segunda parte, buscou-se apresentar o funcionamento da sala MTC e da orientação dos TCC no curso referido, apontando algumas das principais qualidades e dificuldades identificadas. Por fim, apresenta-se a maneira como se intencionou incluir, entre os objetivos do trabalho desenvolvido, a formação dos formadores que atuaram como orientadores de TCC.

\section{A pesquisa na formação docente}

As análises que buscam alternativas para melhorar a qualidade da escola brasileira indicam, invariavelmente, embora não exclusivamente, a importância do investimento na formação dos professores. De acordo a Luce e Andrade:

A formação de professores tem de ser tratada - em um espaço e tempo de diálogo e de articulação, de interatuação entre a educação superior e a educação básica - como uma questão complexa e uma política pública em movimento, por excelência federativa, ou seja, própria do Sistema Nacional de Educação (SNE), constituída e constituinte nesse/desse sistema. (LUCE; ANDRADE, 2017, p. 2).

Um dos desafios dessa formação é equacionar a relação entre teoria e prática, seja na formação inicial, seja na continuada. Entendidas frequentemente como domínios distintos, teoria e prática adquirem maior inteligibilidade na docência se assumidas como dimensões distintas e complementares de um mesmo processo. Isso corresponde a afirmar que ambas são essenciais na atuação dos professores, e, mais do que isso, precisam estar articuladas e igualmente valorizadas na formação desses profissionais. Nesse sentido é que importa enfatizar o aspecto propriamente epistemológico da prática pedagógica e insistir na pertinência da pesquisa como ação cotidiana na escola.

A pesquisa pode, no entanto, aqui ser compreendida de diferentes maneiras. Evidentemente, a pesquisa acadêmica que produz continuamente novos conhecimentos teóricos em várias áreas concernentes ao processo educativo é muito relevante, na medida em que amplia o repertório de uma área e põe à disposição dos profissionais da educação novos saberes. Mas a pesquisa também pode se desenvolver no espaço da escola, seja em colaboração com a produção do campo acadêmico, seja como 
recurso capaz de levar o professor a um processo constante de reflexão sobre a sua prática. Nesse sentido, Bolzan, Isaia e Maciel afirmam:

Não podemos falar em formação docente sem referência aos discentes em seus processos formativos. Assim, à medida que os professores são formadores, também se formam. A construção da aprendizagem de ser professor, portanto, é colaborativa, se faz na prática de sala de aula e no exercício de atuação cotidiana na universidade. (BOLZAN; ISAIA; MACIEL, 2017, p. 59).

Quase sempre reputada como menos importante ${ }^{5}$, a última dimensão apontada tende a ser decisiva para que o professor constitua sua identidade, fortaleça sua autonomia e seja capaz de buscar e de conduzir processos próprios que considere relevantes para sua formação permanente.

Assumir que o professor deva ser um profissional reflexivo implica recusar a compreensão dessa atividade como ancorada numa racionalidade técnica. Pérez Gómez explica que

[...] segundo o modelo da racionalidade técnica, a actividade do profissional é sobretudo instrumental, dirigida para a solução de problemas mediante a aplicação rigorosa de teorias e técnicas científicas. Para serem eficazes, os profissionais das ciências sociais devem enfrentar os problemas concretos que encontram na prática, aplicando princípios gerais e conhecimentos científicos derivados da investigação. (PÉREZ GÓMEZ, 1997, p. 96).

Nesse modelo, teoria e prática são percebidas como em desnível hierárquico, estando a primazia na teoria. Philippe Perrenoud (2002, p. 21) ressalta que, “de modo surpreendente, durante anos, essas formações contínuas desconsideraram a prática dos professores em exercício: o formador dizia-lhes o que era preciso fazer sem perguntar o que eles faziam”. Ora, aos professores cabe, no âmbito da racionalidade técnica, conhecer boas teorias e aplicá-las na sua ação pedagógica. Pérez Gómez ressalta que

[...] ao longo das últimas décadas, a formação de professores tem estado impregnada desta concepção linear e simplista dos processos de ensino, abrangendo normalmente dois grandes componentes: a) um componente científico-cultural, que pretende assegurar o conhecimento do conteúdo a ensinar; b) um componente psicopedagógico, que permite aprender como actuar eficazmente na sala de aula. (PÉREZ GÓMEZ, 1997, p. 98).

Embora o autor fale especificamente dos professores ${ }^{6}$ que atuam em sala de aula, a mesma análise serve para descrever os processos mais frequentes, até pelo menos os anos 1990, na formação dos demais profissionais da educação no Brasil.

5 Ver instigante discussão sobre a necessidade de suprimir a separação entre esses dois âmbitos de pesquisa proposta por Kenneth M. Zeichner (1998). Este autor ressalta que "muitos dos chamados 'projetos de pesquisa colaborativa' ainda deixam os professores na posição de cidadãos de segunda classe ao participarem de um sistema de regras organizadas pela academia" (ZEICHNER, 1998, p. 223).

6 Cabe dizer que se assume, aqui, a compreensão de que as funções de gestão escolar são parte do trabalho docente. 
Contrapondo-se a esse modelo, surgem as discussões em defesa de uma racionalidade prática que oriente os processos de formação docente. Tais proposições "têm em comum o desejo de superar a relação linear e mecânica entre o conhecimento científico-técnico e a prática da sala de aula” (PÉREZ GÓMEZ, 1997, p. 102). Nos processos em que a reflexão sobre a prática está no centro dos investimentos,

[...] parte-se da análise das práticas dos professores quando enfrentam problemas complexos da vida escolar, para a compreensão do modo como utilizam o conhecimento científico, como resolvem situações incertas e desconhecidas, como elaboram e modificam rotinas, como experimentam hipóteses de trabalho, como utilizam técnicas e instrumentos conhecidos e como recriam estratégias e inventam procedimentos e recursos (PÉREZ GÓMEZ, 1997, p. 102).

O processo de reflexão na formação docente, conforme proposto acima, precisa, no entanto, ser conduzido com rigor e sistematização, e o professor precisa proceder ao exercício de distanciamento analítico, necessário a qualquer exame racional. Dessa forma, é possível ao professor produzir conhecimento na escola a partir de sua atuação docente, mediada pela prática reflexiva, que vá ao encontro de suas necessidades específicas, sem dispensar, contudo, o estudo de conhecimentos produzidos em outros espaços. Nesse sentido, em consonância, Perrenoud (2002, p.22-23) destaca que "felizmente, outras modalidades de formação contínua - intervenções em estabelecimentos, acompanhamento de projetos ou de equipes, supervisão - priorizam as práticas e os problemas profissionais”.

A proposição parece plena de coerência se pensamos nas demandas e nos desafios específicos da escola; no entanto, enfrenta a desconfiança de que assim se produza um saber “menos importante”. António Nóvoa ressalta que

[...] é forçoso reconhecer que a profissionalização do saber na área das Ciências da Educação tem contribuído para desvalorizar os saberes experienciais e as práticas dos professores. A pedagogia científica tende a legitimar a razão instrumental: os esforços de racionalização do ensino não se concretizam a partir de uma valorização dos saberes de que os professores são portadores, mas sim através de um esforço para impor novos saberes ditos “científicos”. A lógica da racionalidade técnica opõe-se sempre ao desenvolvimento de uma práxis reflexiva. (NÓVOA, 1997, p. 27).

Em parte, a política de formação na qual se insere o curso de Pós-graduação Lato sensu em Coordenação Pedagógica da Escola de Gestores busca romper com a lógica da racionalidade técnica, ao propor aos cursistas o desenvolvimento de uma pesquisa na escola em que atuam, a partir da qual devem produzir um TCC. Sendo assim, o Projeto Político Pedagógico do Curso determina que

o TCC será concretizado na elaboração de um estudo que culmine em uma proposta de ação que articule a organização do trabalho pedagógico e a busca de um ensino-aprendizagem de qualidade na escola de educação básica onde atua o cursista. Essa proposta de ação procurará, dentre outros aspectos, consolidar os fundamentos teórico-práticos desenvolvidos ao longo do curso por meio dos conteúdos e atividades das salas ambientes. (BRASIL, 2014, p. 15). 
A proposta é que, portanto, partindo da investigação da própria prática, os coordenadores pedagógicos produzam compreensões mais abrangentes acerca dos problemas que vivenciam no cotidiano.

Pensando nisso, o projeto do curso elegeu prioritariamente a pesquisa-ação como abordagem de investigação a ser seguida no desenvolvimento do TCC. A pesquisaação demanda que o pesquisador intervenha em uma problemática, buscando uma transformação. Nessa metodologia, a pesquisa e a ação estão totalmente relacionadas, conforme explicita Franco:

Se alguém opta por trabalhar com pesquisa-ação, por certo tem a conviç̧ão de que pesquisa e ação podem e devem caminhar jun- tas quando se pretende a transformação da prática. No entanto, a direção, o sentido e a intencionalidade dessa transformação serão o eixo da caracterização da abordagem da pesquisa-ação. (FRANCO, 2005, p. 485).

Uma dificuldade, contudo, advém do seguinte aspecto, destacado por Tatiana Bezerra Fagundes:

Atualmente é difícil chegar a um consenso a respeito do conceito de pesquisa-ação, porque ele desenvolveu-se, considerando a argumentação de Lewis (1946), em diferentes campos e tornou-se aplicável a diferentes situações (Tripp, 2005). No campo educacional, a pesquisa-ação pode ser considerada uma estratégia que envolve professores e pesquisadores com o objetivo comum de utilizá-la para criar novas possibilidades para o ensino e, consequentemente, para o aprendizado do aluno. Mas também, nessa mesma área, houve desdobramentos que tornaram a pesquisa-ação uma prática de pesquisa com configurações e objetivos diferenciados. (FAGUNDES, 2016, p. 287-288).

No curso referido, não havia previsão de que o professor-cursista atuasse em conjunto com pesquisadores da universidade. Acrescente-se a isso o fato de que a formação em pesquisa desses profissionais da escola é extremamente exígua, não sendo suficiente, na maior parte dos casos, para a adequada condução de uma pesquisa dessa natureza. Talvez fosse preciso distinguir, em primeiro lugar, a diferença que há entre a investigação da prática como procedimento que visa sistematizar um saber da experiência e desenvolver nos professores competências de reflexão sobre a própria prática, com ganhos evidentes no aperfeiçoamento da atividade docente, e a investigação científico-acadêmica que se desenvolve de acordo com as regras de uma comunidade de pesquisadores, seguindo procedimentos metodológicos específicos, exigindo a publicitação e a revisão pelos pares. Ao apresentar essa distinção, não se pretende afirmar que uma é melhor ou mais importante que a outra, mas sim ressaltar que são atividades, em alguma medida, diferentes, que seguem critérios epistemológicos, em parte, distintos e que têm, no limite, funções sociais também distintas. É evidente também que todo professor pode se formar pesquisador e integrar essas comunidades acadêmicas, produzindo conhecimentos a partir daqueles critérios. Ocorre que, para tanto, é preciso um investimento longo e específico no sentido de 
sua formação como pesquisador, que não é o mesmo tipo de investimento necessário para a formação do profissional da educação. Nem melhor, nem pior, apenas não é de mesmo tipo. Conforme Gatti (2016, p. 163), “compreender e discutir a formação, as condições de trabalho e carreira dos professores, e, em decorrência sua configuração identitária profissional, se torna importante para a compreensão e discussão da qualidade educacional de um país, ou de uma região”. Por fim, carecemos de esforços que busquem viabilizar pesquisas em que a articulação entre os saberes acadêmicos e os saberes da experiência seja o escopo central, conforme argumenta Zeichner (1998), referindo-se ao caso norte-americano.

Antes de propor um tempo estendido para a formação em pesquisa nos cursos para docentes, seria o caso de indagar, como procedimento constante e reflexivo, para que serve a pesquisa na formação de professores. As respostas podem ser variadas. Mas talvez o importante mesmo seja não deixar de fazer a pergunta, sob a pena de mecanizar uma prática sem notar que, assim, pode-se estar esvaziando-a de sentido. Talvez seja possível arriscar dizer que

[...] o que os professores mais podem aprender, em contato com a pesquisa em educação, provém do olhar, das questões que ela suscita, e não tanto dos métodos e das técnicas. É próprio da pesquisa subverter a percepção, revelar o oculto, suspeitar o inconfessável, estabelecer ligações que não saltam aos olhos, reconstituir as coerências sistêmicas sob a aparente desordem (PERRENOUD, 2002, p. 101, grifos do autor).

A sala ambiente Metodologia do Trabalho Científico tinha, no curso de Pósgraduação Lato sensu em Coordenação Pedagógica da Escola de Gestores, a função de prover saberes mínimos essenciais que permitissem aos cursistas o desenvolvimento de uma pesquisa, mesmo que restrita, que aportasse elementos para a escrita de um TCC. Essa tarefa, no entanto, não pareceu poder ser desempenhada a contento no curto tempo a ela destinado. O curso previa 60 horas do currículo para essa formação, em atividades à distância, apartado do convívio com outros pesquisadores, sem possibilidade de integração a comunidades acadêmicas (ida a eventos, participação em seminários de pesquisa, integração em grupo de pesquisa ativo etc.). Ora, a formação de um pesquisador requer muito mais do que o proposto no curso. E, sem terem uma prévia formação sólida em pesquisa, mostrou-se ainda mais difícil que os cursistas desenvolvessem o TCC seguindo a abordagem da pesquisa-ação. Aquilo que deveria ser elemento facilitador no desenvolvimento da pesquisa, por pessoas que não têm experiência em pesquisa ${ }^{7}$, foi afinal o que tornou quase sempre inviável o propósito. Por se tratar de profissionais da ação, que sabem fazer suas atividades cotidianas na escola, que sabem indicar objetivos pedagógicos e propor as ações para sua execução - e que, em contrapartida, não sabem fazer pesquisa - os cursistas muito frequentemente confundiam a pesquisa-ação com o planejamento de ensino, com a

7 Na verdade, alguns cursistas tinham experiência em pesquisa acadêmica, por já terem feito Mestrado ou por estarem em cursos de Mestrado ou de Doutorado. 
elaboração do PPP ou com a execução da avaliação da instituição. O distanciamento necessário para, a partir da própria prática, produzir com rigor novos conhecimentos - como os requeridos no formato de TCC proposto no curso - era dificilmente obtido.

A pergunta, nesse caso, talvez devesse ser: por que se considera que um TCC nos moldes acadêmicos é, de fato, um bom produto final em cursos de formação docente? Ao que parece, apesar da intenção de incorporar a investigação na formação do professor, sugerindo uma concordância com as proposições de formação do professor como profissional reflexivo, mantem-se a ideia da superioridade do saber acadêmico, em detrimento do saber da experiência. A pesquisa na formação docente pode ter por finalidade a produção de conhecimentos na área de educação, mas pode também servir - sem demérito por isso - a muito mais, à medida que instrumentaliza o professor ao distanciamento de sua prática, à análise das situações cotidianas, à busca de soluções, pautada em procedimentos sistemáticos. Nesse sentido, menos do que engajar os professores em pesquisas clássicas e estabelecidas na universidade, valeria à pena

[...] diversificar as formas de pesquisa e privilegiar o que está mais próximo de uma prática reflexiva, dando cada vez menos importância aos produtos e privilegiando os modos de produção, libertando-se das limitações próprias do campo científico para permanecer no interior de uma racionalidade estrita de formação profissional ideal (PERRENOUD, 2002, p. 103).

Não seria o caso de se pensar em outros formatos, mais conformes à especificidade do saber que se produz na atuação prática nas escolas? A ausência de linguagem acadêmica, a falta de revisão rigorosa da literatura, uma escrita sem introdução, capítulos e considerações finais faz esses saberes menos relevantes?

Além disso, o formato proposto - TCC - remete a uma lógica acadêmica, e como tal muito individualizada. O TCC é o produto de uma investigação individual mediada pelas leituras e recomendações de um orientador apenas - e não engaja os profissionais da escola em ações coletivas de formação no âmbito da própria escola nem pressupõe troca de saberes, já que tanto o profissional da escola quanto o profissional da Universidade não chegam a se envolver um com o fazer do outro. Nesse sentido, é pertinente a crítica de António Nóvoa (1997), que nos faz pensar o quanto permanece de racionalidade técnica, afinal, nessas propostas de formação de professores ancoradas na pesquisa:

Práticas de formação contínua organizadas em torno dos professores individuais podem ser úteis para a aquisição de conhecimentos e de técnicas, mas favorecem o isolamento e reforçam uma imagem dos professores como transmissores de um saber produzido no exterior da profissão. Práticas de formação que tomem como referência as dimensões colectivas contribuem para a emancipação profissional e para a consolidação de uma profissão que é autónoma na produção dos seus saberes e dos seus valores. (NÓVOA, 1997, p. 26-27). 
É importante, ainda, enfatizar que, qualquer que seja a intenção no processo de formação - mais voltada para a capacidade de fazer pesquisa, mais centrada na compreensão das situações enfrentadas no cotidiano das escolas, mais direcionada para a solução imediata e objetiva de problemas - falta tempo no âmbito de um curso de aperfeiçoamento como o aqui referido. Os processos formativos, todos, requerem um “demorar-se” que não se encontra previsto na maior parte das opções de formação contínua de professores da atualidade. Considera-se preciso fazer rápido, para contingentes amplos de cursistas, garantindo-se logo alguma certificação. O foco não parece estar, de fato, nas necessidades de formação dos sujeitos - vários dos quais, aliás, já muito familiarizados com essa lógica, fazem um curso de especialização, em seguida de outro. Nos cursos de EaD tem-se ainda o agravante da "quebra da unidade do ensinar/aprender, uma vez que o ensino deixa de ser contemplado para concentrar-se na aprendizagem, concebida como auto-aprendizagem que decorre do acesso à informação ou ao conhecimento" (GATTI; BARRETO; ANDRÉ, 2011, p. 83). Isso não é em si negativo, mas exige prever a necessidade de um tempo extra, imprescindível para que os cursistas se familiarizem e se adaptem ao novo modelo. A avaliação dos cursos de formação de professores em EaD realizados nos últimos anos no Brasil aponta que

[...] os professores [desses cursos] estão longe de encontrar o(a) esperado(a) estudante autônomo(a). Alguns cursos justificam a alta evasão, alegando que os cursistas não estavam aptos a ser alunos a distância, e terminam por não se responsabilizar pelo insucesso deles. Entretanto, o tempo exigido para que os estudantes assumam o papel protagonista nem sempre está dado nos cursos (GATTI; BARRETO; ANDRÉ, 2011, p. 84, grifo nosso).

Assim, é premente afirmar que a falta de tempo para a continuidade da formação, a impossibilidade de integrar os cursistas amplamente nas atividades da universidade, o fato de esses profissionais manterem toda a carga horária de trabalho (às vezes, mais do que 40 horas semanais) durante a participação no curso são itens que inviabilizam uma proposição formativa não fragmentada, mais densa e mais significativa.

\section{Funcionamento de MTC e TCC}

A sala ambiente Metodologia do Trabalho Científico (MTC), espaço curricular do curso de Pós-graduação Lato sensu em Coordenação Pedagógica - $2^{\mathrm{a}}$ edição (2015-2016) - do Programa Nacional Escola de Gestores da Educação Básica (SEB/ MEC), oferecido na Universidade Federal do Rio Grande do Sul, apresentava como característica principal sua transversalidade, uma vez que pretendia perpassar os demais componentes curriculares, desembocando na orientação do Trabalho de Conclusão de Curso (TCC). Sendo assim, essa sala ambiente, que permaneceu aberta até o final do curso, teve como objetivo principal conduzir o processo que culminaria na escrita do TCC. Ou seja, em lugar de apresentar genérica e amplamente questões metodológicas 
sobre o trabalho científico, optou-se, com o propósito de que orientadores e cursistas dispusessem de tempo e de condições suficientes para dedicação aos TCCs, por centrar atenção em aspectos diretamente vinculados à produção do trabalho final.

A sala ambiente MTC foi constituída por turmas de até 47 cursistas, em cada um dos 10 polos, cada turma dispondo de dois professores. No momento da elaboração dos TCCs, as turmas foram divididas, cada professor ficando responsável por orientar metade dos cursistas. Assim, o trabalho de coordenação da sala ambiente MTC e, posteriormente, do desenvolvimento dos TCCs, atribuição das autoras deste artigo, significou acompanhar vinte professores no desenvolvimento de suas atividades de docência e de orientação. Tais atividades engendravam processos organizacionais diversos, com vistas ao desenvolvimento das variadas tarefas referentes às ações que permitem o bom andamento de uma sala ambiente, constituindo-se em trabalho complexo, que demandava tarefas e competências diversas. Embora se pudesse contar com o apoio de outras pessoas envolvidas na organização do curso - responsáveis pela execução financeira, pelo funcionamento do Moodle, pela comunicação com os assistentes de polo, pelo controle da frequência dos cursistas etc. - as tarefas pedagógicas e logísticas de MTC e TCC excediam o razoável para apenas uma pessoa assumir ${ }^{8}$. Assim, com o propósito de melhor orientar os professores para o desenvolvimento das atividades previstas, os trabalhos de coordenação da sala ambiente MTC foram divididos em uma parte mais voltada às questões pedagógicas e outra que se voltou prioritariamente às questões referentes à logística e à organização prática da sala ambiente MTC - e, posteriormente, do TCC - com o propósito de conferir fluência às demandas dos professores.

\subsection{A organização em módulos (MTC)}

O trabalho docente requer, para além da dedicação cotidiana do fazer pedagógico, momentos de reflexão sobre esse fazer. Este objetivo formativo impõe rever teorias, conhecer outras, elaborar e desenvolver projetos por elas inspirados. Por essa razão, propusemos os módulos da sala ambiente $\mathrm{MTC}^{9}$ como etapas sequenciais que, concomitantemente ao desenvolvimento das atividades de estudo propostas pelas demais salas ambientes do curso, pudessem contribuir na construção de um percurso de formação relevante, sem perder de vista a necessidade de se chegar, ao final, à produção de um TCC capaz de apresentar publicamente os resultados desse processo.

A comunicação com os professores da sala ambiente MTC ocorreu principalmente por e-mail, mas foram feitas algumas reuniões com as duplas de professores de cada

8 Nesse momento, então, Caterine Fagundes foi convidada a compartilhar as tarefas da coordenação da sala ambiente. 9 A cada módulo, havia leituras obrigatórias aos cursistas, uma ou duas tarefas que eles deveriam produzir e postar na plataforma do curso, além de um encontro presencial no polo. 
polo, ou com pequenos grupos de professores, e encontros individuais (no período especificamente de orientação dos TCCs). Além disso, foram realizadas duas reuniões com todo o grupo, para planejamento dos encontros presenciais dos módulos III e IV. Em cada um desses momentos, buscava-se o exercício da reflexão sobre a ação, em face do trabalho desenvolvido, bem como a tomada de decisão coletiva sobre os desdobramentos das atividades. Nesse sentido, adotamos, na medida do possível, uma dinâmica dialógica com os 20 professores que atuaram nos 10 polos regionais.

Os conteúdos gerais presentes em cada módulo, bem como o desenvolvimento das atividades nos módulos I e II, foram decididos pelas coordenadoras da sala ambiente MTC. Assim, inicialmente, delineamos as temáticas desenvolvidas pelos professores, com os cursistas, no primeiro encontro, e como se desenvolveriam, em linhas gerais, os demais, que visavam diretamente à elaboração do TCC. Ainda, definimos que nos encontros subsequentes os professores da sala ambiente MTC orientariam os cursistas sobre a metodologia e sobre os encaminhamentos da pesquisa, com o propósito de dar efetivamente início ao desenvolvimento do TCC, no que concerne às leituras e à coleta de dados da pesquisa.

Em linhas gerais, no primeiro módulo, discutiu-se a questão do processo de produção da pesquisa educacional e suas implicações éticas. No segundo módulo, propusemos a apresentação, por parte dos cursistas, das definições da pesquisa que pretendiam realizar. No terceiro e no quarto módulos, trabalhamos questões referentes às possibilidades de análise dos dados da pesquisa e aspectos da escrita do TCC, no que se refere à forma. A seguir, tem-se o detalhamento do trabalho realizado.

\subsubsection{Módulo I}

O Módulo I, de acordo com as orientações, iniciou-se com a apresentação das pessoas envolvidas, a apresentação do funcionamento da disciplina MTC - com a discussão sobre o que é pesquisa em educação - ressaltando alguns conceitos básicos, com a focalização das características da pesquisa-ação e com a discussão da ética na pesquisa.

Definimos que o primeiro encontro presencial seria melhor aproveitado pelos cursistas se ocorresse nos primeiros dias de abertura da sala ambiente e se houvesse uma exposição/discussão sobre a ética na pesquisa, destacando as questões de cópia, citação e plágio. Nesse encontro também foi proposta a reflexão sobre a atuação dos cursistas como coordenadores pedagógicos e, por outro lado, como pesquisadores, ainda que na mesma escola, com o intuito de ressaltar a especificidade dos diferentes papéis - desempenhados concomitantemente por cada um dos cursistas - para o desenvolvimento adequado do trabalho. Para tratar dos temas que seriam trabalhados no primeiro encontro, sugerimos alguns textos e uma matéria de jornal que abordava a questão do plágio, com o propósito de dar início às discussões sobre ética na pesquisa. 
Ao final do encontro presencial, solicitou-se aos cursistas uma breve reflexão individual escrita sobre as impressões e aprendizagens desse primeiro encontro. Salienta-se que foi solicitada uma produção desse tipo ao final de cada encontro, sempre por escrito, sobretudo para comprovar a presença dos alunos. Como tarefa a ser postada na plataforma do curso, os cursistas produziram uma breve análise, discutindo os textos sugeridos sobre ética e plágio na pesquisa.

\subsubsection{Módulo II}

No módulo II, a orientação aos professores foi realizada em reunião em que se propôs que orientassem os cursistas a iniciarem o desenvolvimento do TCC, produzindo uma definição preliminar sobre o tema, sobre como surgiu a ideia de pesquisar tal tema e sobre outros elementos pertinentes à elaboração do trabalho. Sobre os temas de pesquisa, orientou-se que se incentivasse os cursistas a encontrarem soluções para articular os interesses pessoais à investigação, sobre a atuação do coordenador pedagógico.

A intenção da atividade proposta no módulo II foi permitir a reflexão sobre os elementos que estruturam uma investigação e avançar nas definições das pesquisas desenvolvidas pelos cursistas. Para avaliar esse módulo, solicitou-se, além da reflexão escrita, ao final do encontro presencial, a leitura do material referente à produção da pesquisa em educação e também de um texto referente à metodologia da pesquisaação. Além disso, os cursistas indicaram, em uma página, as definições pretendidas para a pesquisa de TCC, e postaram-nas na plataforma do curso.

\subsubsection{Módulo III}

No módulo III, para o qual também se realizou uma reunião geral com os professores, definiu-se como necessário problematizar a empiria, ou seja, a necessidade incontornável de produzir informações novas e originais, na escola em que os cursistas atuam, para o desenvolvimento do TCC. Também foi importante discutir e orientar sobre a necessidade de autorização para a realização das pesquisas nas escolas e a assinatura do Termo de Consentimento Livre e Esclarecido, quando pertinente. Discutiram-se, ainda, procedimentos metodológicos, a partir da leitura prévia dos textos disponibilizados na plataforma do curso, e questões sobre tabulação e análise dos dados, de acordo com cada instrumento de coleta escolhido. O objetivo principal foi tratar com os cursistas como se faz a parte empírica da pesquisa. Para avaliar o módulo III, solicitou-se o desenvolvimento das propostas de pesquisa a partir das orientações individuais e a elaboração dos instrumentos de coleta de dados (questionário, entrevista ou roteiro de observação). 


\subsubsection{Módulo IV}

Finalmente, o módulo IV destinou-se a problematizar a escrita do TCC, bem como o formato do mesmo. Em reunião com todo o grupo de professores, ficou definido que o encontro presencial aconteceria em quatro momentos: (1) apresentação e discussão da estrutura do TCC, realizada juntamente a uma discussão acerca do cronograma de execução do TCC; (2) apresentação sobre a importância do uso da linguagem acadêmica na escrita do trabalho; (3) orientação sobre como realizar o levantamento dos autores/ textos que se pretendia ler sobre o tema escolhido, a partir do Scielo, do Google acadêmico e da plataforma Lattes/CNPq; e (4) avaliação presencial nos 20 minutos finais, consistindo em uma escrita de autoavaliação do processo de aprendizagem nesses quatro módulos, a partir da retomada das escritas anteriores.

A avaliação do Módulo IV ocorreu a partir da postagem de duas tarefas no período em que a sala ambiente esteve aberta: um cronograma pessoal de desenvolvimento do TCC e a listagem dos referenciais teóricos propostos, em consonância com os temas escolhidos.

\subsubsection{A elaboração dos TCC}

Após a segunda recuperação do curso, iniciou-se propriamente a escrita do TCC. Nesse momento, abriu-se uma nova sala ambiente no Moodle com espaços específicos para a postagem das versões preliminares do TCC, da apresentação e da versão final. Nessa etapa, os professores-orientadores (com exceção dos que são docentes do quadro efetivo da UFRGS) foram atendidos individualmente por uma das coordenadoras, para que fosse possível discutir sobre os casos específicos e as eventuais dificuldades de cada um. Nesse momento, puderam expor suas dúvidas quanto a como proceder em relação às orientações dos trabalhos dos cursistas.

\section{Formação dos formadores}

Nessa seção, gostaríamos de insistir sobre a potencialidade do processo descrito na formação reflexiva dos professores-orientadores. Se, por um lado, o Projeto Político Pedagógico do curso propunha, mediante a conviç̧ão sobre a importância do desenvolvimento de uma pesquisa, melhorar a formação dos coordenadores pedagógicos, ampliando a capacidade de investigarem e de compreenderem seu próprio contexto de trabalho, por outro, a composição e o trabalho desenvolvido junto à equipe de professores-orientadores tinham também um objetivo formativo explícito. Assim, havia uma dupla intencionalidade pedagógica no desenvolvimento de MTC e TCC. Tratava-se de garantir a formação dos coordenadores, especificamente no âmbito da pesquisa com vistas à produção de um TCC, ao mesmo tempo em que se visava contribuir na formação profissional dos professores-orientadores. 
Essa intenção foi que guiou a escolha dos integrantes da equipe. Havia efetivamente uma grande dificuldade para compor o grupo de professores apenas com docentes do quadro efetivo da universidade, como era o interesse da coordenação geral do curso. Esse não é um entrave específico dessa versão do curso, nem na universidade em que se desenvolveu. Bernadete Gatti, Elba Barreto e Marli André, no Estado da Arte sobre as políticas docentes no Brasil, produzido em parceria entre a UNESCO e o MEC, com o apoio do CONSED e da UNDIME ${ }^{10}$, mencionam que é preciso considerar as consequências da

[...] não institucionalização dos programas de EaD nas IESs parceiras, quando se tem como foco o trabalho do(a) docente universitário(a) que dele participa. Este(a), também identificado(a) como bolsista, tem suas atividades de ensino na modalidade a distância consideradas como atividades extra, não computadas na carga horária dedicada às atividades de ensino em suas unidades de origem, implicando clara sobrecarga e precarização do trabalho docente (GATTI; BARRETO; ANDRÉ, 2011, p. 84).

Essa situação, que ocorre também na Universidade Federal do Rio Grande do Sul, agrava-se com a profusão de cursos e de programas cujo engajamento dos professores se dá dessa mesma maneira, como bolsistas, resultando em sensível dificuldade na localização de professores do quadro efetivo da universidade com disponibilidade de tempo e de energia para atuarem como professores-orientadores.

Diante da dificuldade mencionada acima, surgiu como possibilidade adequada e viável engajar, na função proposta, alunos de Mestrado, em final de curso, alunos de Doutorado ou, ainda, recém Mestres e recém Doutores. Efetivamente, dos 25 professores que atuaram em MTC e TCC (houve algumas trocas de professores ao longo do curso), apenas 6 eram professores doutores do quadro efetivo da universidade. Essa opção tinha a vantagem de agregar aos objetivos a atuação formativa junto aos próprios professores-orientadores que, estando em meio aos percursos próprios de formação acadêmica, tinham grande interesse em participarem do curso ${ }^{11}$, assim como valorizavam a oportunidade de aprender com a experiência de orientação de pesquisa. Cabe ressaltar que, tratando-se de mestrandos, Mestres e recém Doutores, a probabilidade de que venham a atuar como professores-orientadores em suas trajetórias profissionais é bastante alta.

Nesse sentido, importa reconhecer que a formação para a função de professororientador é desprovida de formalização em nosso meio acadêmico. Em geral, aprendese a orientar trabalhos de pesquisa assumindo efetivamente a orientação de trabalhos

10 UNESCO (Organização das Nações Unidas para a Educação, a Ciência e a Cultura); MEC (Ministério da Educação); CONSED (Conselho Nacional dos Secretários de Educação); UNDIME (União Nacional dos Dirigentes Municipais de Educação).

11 Os professores receberam bolsas para a atuação no curso cujo valor tende a ser mais interessante para mestrandos e doutorandos do que para professores da universidade (devido à diferença de proporção com relação à remuneração base em cada caso). Além disso, é simbolicamente mais rentável nos currículos Lattes daqueles a menção de docência em curso de especialização e a indicação da orientação de TCCs. 
dessa natureza, sem nenhuma mediação e alheio a qualquer proposta pedagógica. Cabe considerar que essa é uma atividade profissional para a qual é preciso constituir uma competência específica, um savoir-faire cuja aprendizagem se dá, de fato, durante a prática profissional. No entanto, isso não implica afirmar que tal aprendizagem deva se dar sem a colaboração intencional de profissionais experientes em tais práticas. O fato de que não haja um curso de "formação de orientadores" não é, afinal, o problema ${ }^{12}$. Isso não corresponde, contudo, a dizer que não possa ou que não deva existir uma formação pensada, proposta, assumida intencionalmente pela universidade.

Nesse sentido é que se vislumbrou a possibilidade da proposição de um percurso formativo junto a esses professores-orientadores, tendo por horizonte as características da prática docente reflexiva, pretendendo contribuir na construção de um habitus ${ }^{13}$. Compreende-se que, na formação inicial de professores (e sugere-se, aqui, por extensão, na formação de professores-orientadores),

[...] é importante ensinar saberes profissionais em seu sentido amplo, expandindo os saberes teóricos oriundos das ciências da educação aos saberes procedimentais deles derivados, transmitidos pela cultura profissional ou estabelecidos pela formalização dos saberes de experiência até então implícitos (PERRENOUD, 2002, p.75, grifos nossos).

Os saberes da experiência, no caso das atividades de orientação de pesquisa, são compartilhados de que modo, em que circunstâncias, em quais momentos? A ideia foi, portanto, criar condições objetivas para o compartilhamento dessas experiências, para a tomada de consciência dos processos formativos dos cursistas, para a tomada de decisões dialogadas. Nesse sentido, em lugar de um plano de trabalho todo definido desde o princípio, optou-se pela realização de reuniões com o grupo de professores, a fim de discutir as possibilidades de organização de cada módulo de MTC, para a apreciação conjunta das vantagens e desvantagens de cada escolha, para a partilha das dificuldades e soluções possíveis. Também foram realizadas reuniões individuais, especificamente no momento de orientação da escrita dos TCCs.

Dentre as dúvidas dos professores, havia todo tipo de questão. Como se percebe nos exemplos abaixo:

No meu polo há diversos cursistas que não estão necessariamente na função de coordenação pedagógica, muito embora todos tenham apontado que exerciam alguma função de gestão.

12 Tendemos a concordar com Perrenoud, quando afirma que as universidades têm dificuldade em ensinar práticas profissionais reflexivas, como a docência. Segundo esse autor, "ao assumir a formação dos professores, com frequência as universidades resistem quando têm que integrar esses 'saberes práticos' ao seu currículo. Sua transmissão é delegada aos responsáveis pelos estágios e aos estabelecimentos escolares. Por esse motivo, como transmite essa missão aos formadores de campo (orientadores pedagógicos, professores dos estágios), a instituição não precisa mais se questionar com seriedade sobre a natureza desses saberes" (PERRENOUD, 2002, p. 72-73). $\mathrm{O}$ autor se refere especificamente à formação dos professores da educação básica, mas podemos compreender que um curso de "formação de orientadores", se existisse, sofreria as mesmas limitações.

13 Assume-se, aqui, o conceito de habitus conforme o propõe Pierre Bourdieu, como sistema de esquemas de percepção e ação, como uma "gramática” geradora da prática. 
Como o intuito é promover a pesquisa-ação, não seria incongruente solicitar aos cursistas o desenvolvimento de um trabalho (que obviamente envolve a prática e a pesquisa) de algo que efetivamente eles não estão executando?

Como havia lhe falado em nossa reunião [pessoa A], corrigi o trabalho da aluna $\mathrm{X}$ na recuperação... já que esta postou a atividade do módulo IV só no dia 08 DE JANEIRO, período da recuperação... E agora [pessoa B] quer que eu corrija, sendo que a aluna postou na recuperação e no módulo IV (2 meses fora do prazo). A [pessoa A] havia me falado que tomei a atitude correta! Não gostaria que demonstrasse ser negligencia da minha parte em relação à correção dos trabalhos.... Peço ajuda de vocês!!!

Sobre a avaliação, tenho algumas dúvidas:

- Na correção da atividade presencial, colocamos a nota no trabalho do cursista? Devemos colocar também algum tipo de parecer?

- No moodle, além da nota (que é a soma da atividade postada, com a presencial > 8 +2), devemos colocar também um comentário para cada avaliação?

- Qual o prazo para postarmos o resultado das avaliações no moodle?

- Havia entendido inicialmente, que o resultado das avaliações seria por conceito e não por notas, de acordo com definição da coordenação do curso na UFRGS, mas depois disso seguimos recebendo orientações relacionadas a notas. Concluo que o registro das avaliações das atividades será por notas, conforme consta no moodle, correto?

A convicção está em que esse compartilhamento possa prover um repertório de esquemas de ação, recursos de identificação de situações, capacidades que permitam a esses sujeitos lançar mão de estratégias analógicas que lhes favoreçam efetuar transferências e inventar soluções originais em situações novas (PERRENOUD, 2002). Cabe, nesse sentido, reconhecer a importância de agir para que se aprenda a "agir”, mas não no sentido de automatizar respostas a situações típicas, e sim de identificar padrões e de mobilizar saberes diversos, teóricos ou da experiência, para a condução de uma prática criativa e eficaz. Para tanto, parece imprescindível um processo longo e partilhado, em que se tenha tempo de incorporar novos esquemas de ação e também de se tomar consciência desse processo, sem o que dificilmente se constitui uma prática reflexiva.

\section{Considerações finais}

A experiência de coordenação da atuação de professores-orientadores de TCC no curso de Pós-graduação Lato sensu em Coordenação Pedagógica, do Programa Nacional Escola de Gestores da Educação Básica, suscita a reflexão sobre dois aspectos mais destacados. De um lado, tem-se a percepção da insuficiência, em termos de tempo e de recursos, para levar a cabo uma sólida experiência de formação continuada aos profissionais inscritos no curso - o que mereceria, no entanto, maiores estudos para 
uma afirmação conclusiva. De outro, impõem-se a evidência da potencialidade da atuação nesses cursos como processo de formação dos professores-orientadores.

No que se refere à formação dos coordenadores pedagógicos que atuam nas escolas de educação básica, vários parecem ser os elementos que dificultam sobremaneira seu engajamento substancial na atividade de formação proposta. Isso não significa que deixem de se dedicar às atividades propostas no âmbito do curso - muitos se dedicam completamente à execução da proposta de formação feita - nem é o mesmo que afirmar que esses cursistas não aprendem no decurso dessa experiência formativa, ou que deixem de considerar válida e de boa qualidade a proposta. Muitos deles destacam, agradecidos, a possibilidade de acesso a um curso desse tipo. Este é inegavelmente o maior mérito dos cursos EaD. No entanto, de modo geral, ao que tudo indica, os coordenadores pedagógicos participam do curso ao mesmo tempo em que seguem responsáveis por muitas demandas na escola em que atuam, frequentemente trabalhando mais do que 40 horas por semana. Ora, isso desvela o fato de que é à custa de uma energia pessoal extra que esses profissionais buscam melhorar sua formação. Das redes de ensino, embora se solicite a anuência para que seus profissionais participem do curso, obtém-se muito pouca colaboração, sendo várias vezes difícil, inclusive, a negociação de horários para que os profissionais possam participar das poucas horas presenciais previstas no curso. Evidentemente, sobram apenas as horas de "descanso" para que os coordenadores pedagógicos desenvolvam as leituras e as demais atividades didáticas propostas. Não é de se estranhar os altos índices de abandono. Essas percepções, oriundas das falas dos formadores, não foram foco de investigação neste artigo, mas apontam pistas para futuras pesquisas que nos permitam melhor compreender as condições na quais a formação continuada tem se realizado. Nesse mesmo sentido, mencionamos a seguir outros elementos cujo aprofundamento merece ser realizado proximamente.

Do ponto de vista de quem atua na universidade, fica a sensação de que a esses profissionais o curso acena com mais do que consegue oferecer. Muitos dos cursistas mostram-se entusiasmados com a possibilidade de "frequentarem" um curso de Pósgraduação numa universidade prestigiosa. No entanto, seria importante refletir sobre o quanto, de fato, eles têm de contato com as atividades que dão a essas universidades o prestígio que têm. Os cursistas têm, quando muito, contato nos poucos encontros presenciais e à distância com alguns docentes da universidade. Mas, mesmo nesses casos, quanto se vêm integrados em projetos, práticas e atividades típicas da universidade? Falta, ao que parece, a possibilidade de maior integração efetiva à universidade. Não se pode deixar de mencionar, ainda, que o excesso de cursistas em cada polo diminui muito a interação dos professores com cada um dos cursistas.

Outra questão que merece alguma reflexão é o fato de que os cursos dessa feição não são previstos como processos de formação que envolvam o coletivo da escola. Os coordenadores buscam individualmente os cursos e, embora tenham o consentimento 
da escola para frequentá-los, não está previsto que a formação seja partilhada com os demais profissionais da instituição em que atuam. Se fazem isso é em função de inciativas e de habilidades gregárias individuais. Como nos sugere Nóvoa (1997), práticas de formação que abarcam o coletivo da escola contribuem para fortalecer a profissão; ampliam também os vínculos entre colegas de trabalhos, favorecem o engajamento em projetos partilhados na escola etc., o que não é, em geral, o caso no curso aqui mencionado.

Por fim, contudo, cabe destacar que, se são muitas as dificuldades enfrentadas para que um curso dessa natureza potencialize processos consistentes de formação docente (e em nenhum caso se está afirmando que não seja possível que isso ocorra), a experiência de coordenação dos professores-orientadores que atuaram nesse curso mostrou o quanto esses processos podem ser relevantes para a formação desses últimos. Ao contrário de configurarem uma alternativa precária, já que são colocados nessa função devido à falta de professores da universidade para isso, o engajamento de mestrandos, doutorandos, recém Mestres e recém Doutores permitiu, conforme se pôde constatar nessa experiência, a condução de um trabalho sério e compromissado, e abriu a possibilidade de se constituir uma ação coletiva e partilhada de formação docente desses sujeitos, no âmbito da universidade. Assim, interessa aqui ressaltar o potencial da atuação como orientadores de TCC de sujeitos cuja formação acadêmica está em curso, tanto para a condução com qualidade da orientação de número muito expressivo de TCCs quanto para a formação de professores-orientadores em um processo cuja coordenação geral dos trabalhos funcionou também como, de certo modo, partilha e supervisão de um aprendizado (a saber, como orientar trabalhos acadêmicos) que costuma ser solitário.

\section{Referências}

AZANHA, José Mário Pires. A formação do professor e outros escritos. São Paulo: Editora Senac, 2006.

BOLZAN, Doris Pires Vargas; ISAIA, Silvia Maria de Aguiar; MACIEL, Adriana Moreira da Rocha. Formação de professores: a construção da docência e da atividade pedagógica na Educação Superior. Revista Diálogo Educacional, v. 13, n. 38, p. 4968, 2017. 
BRASIL. Projeto Pedagógico do Curso de Pós-Graduação Lato Sensu em Coordenação Pedagógica. Brasília: Ministério da Educação, Secretaria de Educação Básica, Programa Nacional de Gestores da Educação Básica Pública, 2009.

FAGUNDES, Tatiana Bezerra. Os conceitos de professor pesquisador e professor reflexivo: perspectivas do trabalho docente. Revista Brasileira de Educação, Rio de Janeiro, v. 21, n. 65, p. 281-298, abr./jun. 2016.

FRANCO, Maria Amélia Santoro. A Pedagogia da pesquisa-ação. Educação e Pesquisa. Revista da Faculdade de Educação da USP, São Paulo, v. 31, n. 3, p. 483-502, dez. 2005.

GATTI, Bernadete Angelina; BARRETO, Elba Siqueira de Sá; ANDRÉ, Marli Eliza Dalmazo de Afonso. Políticas docentes no Brasil: um estado da arte. Brasília: UNESCO, 2011.

GATTI, Bernardete A. Formação de professores: condições e problemas atuais. Revista Internacional de Formação de Professores, v. 1, n. 2, 2016.

LUCE, Maria Beatriz; ANDRADE, Fernanda Borges de. Formação de professores: a política e as diretrizes curriculares. Em Aberto, v. 30, n. 98, 2017.

MÓNICO, Lisete S. et. al. A observação participante enquanto metodologia de investigação qualitativa. Actas Investigação Qualitativa nas Ciências Sociais. $6^{\circ}$ Congresso Ibero Americano de Investigação Qualitativa, Salamanca, v. 3, p. 724733, 2017.

NÓVOA, António. Formação de professores e profissão docente. In: NÓVOA, António (Org.). Os professores e a sua formação. 3. ed. Lisboa: Publicações Dom Quixote/ Instituto de Inovação Educacional, 1997. p. 15-33.

PÉREZ GÓMEZ, Angel. O pensamento prático do professor: a formação do professor como profissional reflexivo. In: NÓVOA, António (Org.). Os professores e a sua formação. 3. ed. Lisboa: Publicações Dom Quixote/Instituto de Inovação Educacional, 1997. p. 93-114.

PERRENOUD, Philippe. A prática reflexiva no ofício de professor - profissionalização e razão pedagógica. Porto Alegre: Artmed, 2002. 
ZEICHNER, Kenneth M. Para além da divisão entre professor-pesquisador e pesquisador acadêmico. In: GERALDI, Corinta Maria Grisolia; FIORENTINI, Dario; PEREIRA, Elisabete Monteiro de A. (Orgs.). Cartografias do trabalho docente: professor(a)pesquisador(a). Campinas, SP: Mercado das Letras, 1998. p. 207-236.

Recebido em: 15/07/2016

Aprovado em: 01/04/2018 